\title{
Comparison of serological specificity of anti-endotoxin sera directed against whole bacterial cells and core oligosaccharide of Escherichia coli J5-tetanus toxoid conjugate ${ }^{\star \star}$
}

\author{
Jolanta Lukasiewicz ${ }^{1}$, Wojciech Jachymek ${ }^{1}$, Tomasz Niedziela ${ }^{2}$, \\ Malgorzata Malik-Gebicka ${ }^{1}$, Monika Dzieciatkowska ${ }^{1}$ and Czeslaw Lugowski ${ }^{1}$ \\ ${ }^{1}$ Department of Immunochemistry, Ludwik Hirszfeld Institute of Immunology and Experimental \\ Therapy, Wroctaw, Poland; ${ }^{2}$ Swedish University of Agricultural Sciences, Uppsala, Sweden
}

Received: 08 August, 2002; accepted: 20 August, 2002

Key words: endotoxin, core region, neoglycoconjugate, Escherichia coli J5, antibody

\begin{abstract}
The rough mutants of Gram-negative bacteria are widely used to induce protective antisera but the nature of the target epitope for such antibodies is not precisely defined. Endotoxin is one of several antigens present on the surface of bacterial cells, which are able to elicit specific antibodies. We studied the specificity of antibodies produced against a conjugate of $E$. coli $\mathrm{J} 5$ endotoxin core oligosaccharide with tetanus toxoid. The use of chemically defined antigen for immunisation excludes the possibility of production of antibodies against other cell surface antigens. A comparison of this monospecific anti-endotoxin serum with antiserum against $E$. coli $J 5$ whole cells was performed in order to distinguish the role that endotoxin core oligosaccharide plays in the interaction with humoral host defences from that of other potentially important Gram-negative bacterial surface antigens. The reactivity of both sera with smooth and rough lipopolysaccharides was determined in ELISA, immunoblotting
\end{abstract}

\footnotetext{
${ }^{\star}$ Results of these studies were presented at 6 th Conference of the International Endotoxin Society, Paris 2000, J Endotoxin Res., 6: P-155.

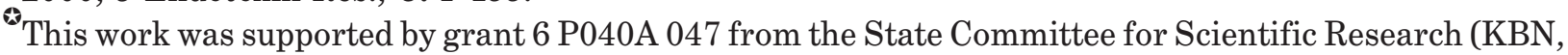
Poland).

Scholarship for Jolanta Lukasiewicz from the Foundation for Polish Science is acknowledged.

${ }^{\otimes}$ Corresponding author: Jolanta Lukasiewicz, Department of Immunochemistry, Ludwik Hirszfeld Institute of Immunology and Experimental Therapy, Polish Academy of Sciences, R. Weigla 12, 53-114 Wrocław, Poland; tel. (48 71) 3732274 ext. 365; fax: (48 71) 373 2274; e-mail: czaja@iitd.pan.wroc.pl

Abbreviations: Ab, antibody; FAB-MS, fast atom bombardment mass spectrometry; FACS, fluorescence activated cell sorter; FCS, fetal calf serum; GLC-MS, gas liquid chromatography-mass spectrometry; IgG, immunoglobulin G; IL-6, interleukin 6; Kdo, 3-deoxy-D-manno-oct-2-ulosonic acid; OMP, outer membrane protein; NO, nitric oxide; OS, oligosaccharide; OS J5-TT, E. coli J5 core oligosaccharide-tetanus toxoid conjugate; $\mathrm{PBS}$, phosphate-buffered saline; $\mathrm{TNF} \alpha$, tumour necrosis factor.
} 
and by flow cytometry. Both antisera reacted with similar specificity with most lipopolysaccharides of identical or related core type. Less distinct reactions with endotoxins of the antibacterial serum in comparison with the anti-conjugate serum were found in all serological tests. LPS of $E$. coli $\mathrm{O} 100$ that showed the strongest reactions with both sera was used to stimulate IL-6, TNF $\alpha$ and nitric oxide production by the J-774A.1 cell line. Both sera were used to inhibit that stimulation and no inhibitory effects of the examined sera in comparison with non-immune serum were observed.

Lipopolysaccharide (LPS) is the main component of the outer membrane of the cell envelope of Gram-negative bacteria. Lipopolysaccharide is responsible for the initiation of endotoxic shock, therefore this molecule is a target for new preventive and therapeutic strategies. It has been found that endotoxins derived from different bacterial species share common basic structure (Holst et al., 1996). LPS consists of a polysaccharide part that includes an O-specific chain and core oligosaccharide (OS) covalently linked to lipid A. Most of the antibodies produced during immunisation with bacterial cells are directed against the O-specific part of endotoxin. The variability of O-serotypes among bacteria of one species excludes the use of anti-LPS antibodies as broad-protective candidates for therapeutic intervention in the case of infection. The core oligosaccharide is a conserved part of endotoxins. Structural analysis of lipopolysaccharides isolated from different strains of bacteria show lower variability among the core oligosaccharide parts in comparison with $\mathrm{O}$-specific chains. These findings have prompted investigators to use rough mutants that lack the O-specific polysaccharide in an attempt to induce protective anti-core endotoxin antibodies. Such anti-core antibodies obtained as a result of immunisation with whole cells of rough mutants can recognise core oligosaccharide epitopes in the LPS structure on the surface of bacterial cells.

$E$. coli J5 is the most frequently studied rough mutant, isolated by Elbein and Heath (Elbein \& Heath, 1965; Ziegler et al., 1973) from a parent culture of $E$. coli serovar O111:B4. E. coli J5 produces LPS that lacks O-specific chain and possesses an incomplete core oligosaccharide of the Rc chemotype
(Muller-Loennies et al., 1994; Muller-Loennies et al., 1999). Numerous experiments have been performed to examine therapeutic properties of antibodies directed against $E$. coli J5 whole cells during the last three decades. However, the results obtained by different groups were contradictory, regarding the existence of these broadly cross-reactive and cross-protective antibodies and the nature of the target epitope (Hustinx et al., 1997). Several explanations of the lack of cross-protective activity of antibodies against whole cells of $E$. coli J5 were proposed. The heterogeneity of $E$. coli J5 vaccine and protection via anti-OMP (outer membrane proteins) antibodies are the main reasons of such a discrepancy in outcomes reported for cross-protection studies with $E$. coli J5 antisera. The antigenic and immunogenic differences in LPS of $E$. coli J5 vaccine strains depend on their origin and on the growth conditions. Some of the examined strains were identical with the original J5 strain and were unable to synthesise LPS with complete core structure substituted with O-specific polysaccharide. Several strains were found to contain LPS of the R3 chemotype while several others expressed complete R3 core structure and $\mathrm{O}$-antigen, as a result of a reversion of the J5 mutant to the smooth form (Appelmelk et al., 1986; Evans et al., 1992; Appelmelk et al., 1993). It was shown that antiserum against $E$. coli $\mathrm{J} 5$ contains antibodies reactive with OMP of heterogeneous Gram-negative bacteria. These results suggested that some of the in vivo protection described by earlier investigators could be conferred by anti-OMP IgG (Brauner et al., 1986; Hellman et al., 1997; Hellman \& Warren, 1999; Hellman et al., 2000). These findings prompted us to compare the specificity of 
anti-E. coli J5 antiserum with antibodies obtained against chemically defined $E$. coli J5 LPS core oligosaccharide conjugated with tetanus toxoid (OS J5-TT).

Several antigens present on the surface of bacteria are able to elicit specific antibodies during immunisation with bacterial cells. We examined the immunogenicity and cross-reactivity of covalent conjugates of core oligosaccharides of $E$. coli R1, R2, R3, J5 and Salmonella Ra LPSs in our previous study (Lugowski et al., 1996a; 1996b). The covalent conjugate of $E$. coli J5 core oligosaccharide with tetanus toxoid is an antigen with defined structure. The use of this conjugate to elicit anti-bacterial serum excludes the possibility of antibodies production against additional cell surface antigens such as OMP, E. coli R3 complete core structures and O-specific chains of $E$. coli O111:B4 LPS. We obtained and compared rabbit sera against $E$. coli J5 and the glycoconjugate (OS J5-TT).

This work was carried out in order to get insight into the role that endotoxin core oligosaccharide, a potentially important Gramnegative bacterial surface antigen, plays in the interaction with humoral host defences.

\section{MATERIALS AND METHODS}

Bacteria. The rough mutant strains of E. coli and Salmonella typhimurium were kindly provided by Prof. Helmut Brade (Research Center Borstel, Germany). The strains of Bordetella pertussis were obtained from the Sera and Vaccines Central Research Laboratory (Warsaw, Poland). Plesiomonas shigelloides O54 was obtained from the collection of the National Institute of Public Health (Prague, Czech Republic). Other strains of smooth bacteria were obtained from the collection of the Institute of Immunology and Experimental Therapy (Wrocław, Poland). Bacteria were grown in liquid medium, killed with $0.5 \%$ phenol and centrifuged using a CEPA flow laboratory centrifuge (Petersson et al., 1997).
Tetanus toxoid. Tetanus toxoid preparation was obtained from Biomed (Kraków, Poland).

Cell lines. Cells of the mouse macrophagelike cell line J-774A.1 were obtained from the German Collection of Microorganisms and Cell Cultures (Braunschweig, Germany), the TNF $\alpha$-sensitive WEHI 164.13 mouse fibrosarcoma cells were kindly donated by Prof. Michał Zimecki (Institute of Immunology and Experimental Therapy, Wrocław, Poland). Murine macrophage cell line J-774A.1 cells were grown in Dulbecco's medium supplemented with $10 \%$ foetal calf serum (FCS) (Gibco, Biocult, Glasgow, U.K.). WEHI 164.13 cells were grown in RPMI 1640 supplemented with $10 \%$ FCS, $2 \mathrm{mM}$ L-glutamine, $1 \mathrm{mM}$ pyruvic acid and $4 \mathrm{mM}$ 2-mercaptoethanol.

Lipopolysaccharide and core oligosaccharides. LPS of E. coli J5 was extracted from bacterial cells by the phenol/chloroform/petroleum ether procedure (Galanos et $a l ., 1969)$. The yield of LPS was $2 \%$ of dry bacterial mass. LPS was degraded by treatment with $1.5 \%$ acetic acid at $100^{\circ} \mathrm{C}$ for $1 \mathrm{~h}$. The reaction mixture was centrifuged to separate lipid A and supernatant was freeze-dried as described earlier (Niedziela et al., 1996). The water-soluble mixture of oligosaccharides was fractionated on a Bio-Gel P-10 column $(1.6 \times$ $100 \mathrm{~cm}$, equilibrated with $0.05 \mathrm{M}$ pyridine/ acetic acid buffer, pH 5.6) (Petersson et al., 1997). Eluates were monitored with a Knauer differential refractometer. The mixture of oligosaccharides eluted from Bio-Gel P-10 was separated on a Bio-Gel P-2 column $(1.8 \times 90$ $\mathrm{cm}$, in the same buffer). Three fractions were eluted, freeze-dried and checked by ${ }^{1} \mathrm{H}$ NMR and matrix-assisted laser-desorption/ionisation time-of-flight mass spectrometry (MALDI-TOF).

Analytical procedures. Sugars were analysed as their alditol acetates by GLC-MS (gas liquid chromatography-mass spectrometry). Methylations were performed according to the method of Hakomori (1964) and methylated sugars were analysed by GLC-MS as pre- 
viously described (Petersson et al., 1997). GLC-MS was carried out with a HewlettPackard 5971A system using the HP-1 fused-silica capillary column $(0.2 \mathrm{~mm} \times 12 \mathrm{~m})$ and the temperature program $150-270^{\circ} \mathrm{C}$ at $8^{\circ} \mathrm{C} \min ^{-1}$. Dephosphorylation was carried out by treatment of core oligosaccharide sample $(5 \mathrm{mg})$ with $48 \% \mathrm{HF}(1 \mathrm{ml})$ at $4^{\circ} \mathrm{C}$ for 3 days.

Mass spectrometry. MALDI-TOF, in positive and negative ion mode, was run on a Kratos Kompact-SEQ instrument. 2,4,6-Trihydroxyacetophenone monohydrate ( $1 \%$ in acetonitrile/water, 1:1, v/v) was used as matrix for the analysis of the core oligosaccharide of $E$. coli J5 LPS. Fast atom bombardment (FAB) mass spectra were recorded on a JEOL JMS-SX/SX-102 A four sectors tandem mass spectrometer by bombardment of samples, dissolved in a glycerol matrix, with Xe atoms of the average translational energy of 6 $\mathrm{keV}$.

NMR spectroscopy. NMR spectra of the oligosaccharides were obtained for ${ }^{2} \mathrm{H}_{2} \mathrm{O}$ solutions at $35^{\circ} \mathrm{C}$ on a Bruker DRX 600 spectrometer. All spectra were obtained using acetone $\left(\delta_{\mathrm{H}} 2.225\right.$ and $\left.\delta_{\mathrm{C}} 31.00\right)$ as internal reference. In the ${ }^{31} \mathrm{P}$ NMR experiments, $80 \%$ phosphoric acid was used as external reference. Oligosaccharides were repeatedly exchanged with ${ }^{2} \mathrm{H}_{2} \mathrm{O}$ with intermediate lyophilization prior to analysis. The data were acquired and processed using standard Bruker software.

Preparation of core oligosaccharide conjugate with tetanus toxoid (TT). The conjugation was carried out according to the method of Jennings and Lugowski using reaction of reductive amination (Jennings \& Lugowski, 1982). The core oligosaccharide was oxidised with $0.75 \% \mathrm{NaIO}_{4}(1 \mathrm{ml})$ in darkness at $4^{\circ} \mathrm{C}$ for $30-45 \mathrm{~min}$. The excess of periodate was destroyed by adding ethylene glycol. After purification on a Sephadex G-25 $(2.6 \times 90 \mathrm{~cm})$ column equilibrated with 0.02 $\mathrm{M}$ pyridine/ $\mathrm{CH}_{3} \mathrm{COOH}$ buffer, $\mathrm{pH} 5.4$, the product was freeze-dried. The oxidised core oligosaccharide of $E$. coli J5 LPS was dis- solved in $0.5 \mathrm{M} \mathrm{K}_{2} \mathrm{HPO}_{4}$, pH 9.0 (1 ml). Tetanus toxoid (3 mg), $\mathrm{NaBCNH}_{3}(10 \mathrm{mg}$ ) and one drop of chloroform were added to the solution. The reaction mixture was kept in sealed vials for 12 days at $37^{\circ} \mathrm{C}$ and then applied to a Sephadex G-100 column $(1.6 \times 100 \mathrm{~cm})$ equilibrated with phosphate-buffered saline (PBS), $\mathrm{pH}$ 7.5. Fractions containing the conjugate were concentrated by ultrafiltration.

Immunisation procedure. Rabbits were immunised with $50 \mu \mathrm{g}$ of the conjugate suspended in Freund's complete adjuvant at days 0 and 21 as described (Lugowski et al., 1996b). The animals were bled 14 days after the second injection. Polyclonal antibodies against the whole bacterial cells of $E$. coli J5 were obtained by intravenous immunisation of rabbits with freeze-dried bacteria suspended in PBS as described (Lugowski \& Romanowska, 1978).

Microprecipitin test. Quantitative microprecipitin test was carried out by the method of Kabat \& Mayer (1967). The reaction mixture contained in addition $2 \%$ polyethylene glycol 6000.

SDS/PAGE was carried out by the method of Laemmli (1970) with modifications (Romanowska et al., 1988) and the LPS bands were visualised by silver staining (Tsai \& Frasch, 1982).

ELISA and ELISA inhibition test. ELISA was performed by a modification of the method of Voller et al. (1975) as previously described (Lugowski et al., 1996b).

In the inhibition studies the antiserum (100 $\mu \mathrm{l})$ at concentration twice as high as that giving $\mathrm{A}_{405}$ in the range 0.8-1.1 was mixed with $100 \mu \mathrm{l}$ of inhibitor solution and incubated for $1 \mathrm{~h}$ at $37^{\circ} \mathrm{C}$. The mixture $(100 \mu \mathrm{l})$ was transferred into the wells of a microtiter plate coated with $E$. coli J5 LPS and the reaction was carried out at room temperature for 15 min. The washing of the wells, incubation with second antibody conjugated with alkaline phosphatase and colour development were performed as described earlier (Lugowski et al., 1996b). 
Immunoblotting. Immunoblotting was performed on the SDS/PAGE separated LPS fractions as described earlier (Lugowski et al., 1996a).

Immunofluorescence procedures. Bacteria were cultured in nutrient broth to logarithmic phase of growth, harvested, washed and suspended in PBS to an $\mathrm{A}_{600}$ of $0.6\left(4 \times 10^{8}\right.$

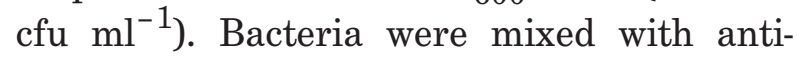
serum (0.5 ml, 100 times diluted) and incubated at room temperature for $2 \mathrm{~h}$. Non-immune sera were employed as negative controls. After three-times washing with PBS the bacteria were incubated for $3 \mathrm{~h}$ with FITC (fluorescein isothiocyanate)-labelled goat anti-rabbit IgG as a detecting antibody. The bacteria were washed with PBS and suspended in $0.5 \%$ paraformaldehyde (Lugowski et al., 1996b).

Fluorescence activated cell sorter analysis. FACS analysis was performed using a FACSscan fluorescence-activated cell sorter (Becton Dickinson; argon-ion laser $488 \mathrm{~nm}$ at $14 \mathrm{~mW}$ ). Twenty-thousand bacteria were evaluated in each analysis. Narrow angle forward light scatter and FITC (green fluorescence) emission signals were collected. Bacterial aggregates were electronically excluded on the basis of light scatter signals (Lugowski et al., 1996b).

\section{Inhibition of TNF $\alpha, I L-6$ and NO release} in J-774A. 1 cells. J-774A. 1 cells were plated in 24-well tissue culture plates (Nunc, Denmark) at $1 \times 10^{6}$ cells/well in $1 \mathrm{ml}$ of Dulbecco's medium supplemented with $10 \%$ (v/v) FCS, incubated $16 \mathrm{~h}$ and washed twice with serum free medium. The lipopolysaccharide isolated from smooth strain of $E$. coli $\mathrm{O} 100$ (10 ng) was used as a stimulant. The cells were incubated in $1 \mathrm{ml}$ of medium with: (A) LPS and anti-OS J5-TT conjugate rabbit serum $(100 \mu \mathrm{l})$, (B) LPS and anti- $E$. coli J5 serum (100 $\mu \mathrm{l})$, (C) LPS and non-immune serum $(100 \mu \mathrm{l})$ and (D) PBS. The supernatants were collected to determine TNF $\alpha$ (after $4 \mathrm{~h}$ ), IL-6 (after $24 \mathrm{~h}$ ) and total concentration of nitrite and nitrate as stable metabolites of NO (after $48 \mathrm{~h}$ ) and stored at $-80^{\circ} \mathrm{C}$ until determination.

TNFa bioassay. TNF $\alpha$ concentration in the supernatants was determined in the cytotoxic assay using the WEHI 164.13 bioassay (Espevik et al., 1986). Briefly, WEHI 164.13 cells were seeded at a concentration $2 \times 10^{4}$ cells/well in a 96-well plate (Nunc, Denmark). Decreasing dilutions of the assayed supernatants in RPMI 1640 medium ( $25 \mu \mathrm{l}$ ) were added to the target cells in the presence of actinomycin D $\left(1 \mu \mathrm{g} \mathrm{ml}^{-1}\right)$. After incubation for $20 \mathrm{~h}$, cell viability was determined by MTT [3-(4,5-dimethylthiazol-2-yl)-2,5-diphenyltetrazolium bromide] colorimetric assay. The concentration of TNF $\alpha$ was expressed as $\mathrm{pg} \mathrm{ml}^{-1}$, using mouse recombinant TNF $\alpha$ (Pharmingen, U.S.A.) as a standard. The detection limit of the WEHI 164.13 cell cytotoxicity assay was approximately $0.15 \mathrm{pg} \mathrm{ml}^{-1}$.

IL-6 assay. IL-6 activity was determined using the OptEIA ${ }^{\text {TM }}$ kit (Pharmingen, U.S.A.). The test was performed using polystyrene microtiter plates (Maxisorb, Nunc, Denmark) according to the instructions provided. TMB (3,3',5,5'-tetramethylbenzidine) reagent set provided by Pharmingen was used as a substrate for horseradish peroxidase. The absorbance was measured at $450 \mathrm{~nm}$ using a Behring EL311s microplate reader.

Nitric oxide determination. Total nitrite + nitrate $\left(\mathrm{NO}_{2}{ }^{-}+\mathrm{NO}_{3}{ }^{-}\right)$in the supernatants collected from stimulated J-774A.1 cells was determined by the Griess reaction in $100 \mu \mathrm{l}$ of the test samples. Nitrate was reduced by nitrate reductase. Briefly, $50 \mathrm{mU}(5 \mu \mathrm{l})$ of nitrate reductase (EC 1.6.6.2) and $1 \mu \mathrm{l}$ of NADPH (stock, $0.65 \mathrm{mg}$ in $100 \mu \mathrm{l}$ ) in Tris $/ \mathrm{HCl}$ buffer, $\mathrm{pH}$ 7.5, were added to the tested supernatant $(100 \mu \mathrm{l})$. The reaction was carried out at $25^{\circ} \mathrm{C}$ for $30 \mathrm{~min}$, followed by the colorimetric test using Griess reagent. Samples were incubated for $10 \mathrm{~min}$ at room temperature with $100 \mu \mathrm{l}$ of Griess reagent (1\% sulfanilamide, $0.1 \% \mathrm{~N}$-(1-naphthyl)-ethylene-diamine dihydrochloride in $5 \% \mathrm{H}_{3} \mathrm{PO}_{4}$ ). Absorbance was measured at $540 \mathrm{~nm}$ using a 
Behring EL311s microplate reader. $\mathrm{NO}_{2}{ }^{-}$concentrations were calculated by comparison with a standard curve prepared using $\mathrm{NaNO}_{2}$ (Schmidt, 1995).

MTT colorimetric assay for cell growth / cell killing. The method was performed according to Mosmann (1983) with a modification (Hansen et al., 1989). Briefly, MTT (5 mg $\mathrm{ml}^{-1}$ stock solution) was added ( $25 \mu \mathrm{l}$ per well) at the end of the assay and after $3 \mathrm{~h}$ of incubation at $37^{\circ} \mathrm{C}$ in $100 \%$ humidity, $100 \mu \mathrm{l}$ of lysis buffer (20\% SDS, 50\% dimethylformamide, $\mathrm{pH}$ 4.7) was added. After additional overnight incubation, absorbance was measured at 562 nm.

Statistical analysis. Assays were performed using triplicate cultures. Data are expressed as means \pm standard deviation ( \pm S.D.) and differences between them were analysed using Student's $t$-test. Differences at $P<0.05$ were considered significant.

\section{RESULTS AND DISCUSSION}

\section{Structural analysis of the core oligosaccharide}

Core oligosaccharides were purified by gel filtration on BioGel P-10 of the water soluble fraction obtained after mild acid hydrolysis of $E$. coli J5 lipopolysaccharide and further purified on a BioGel P-2 column. The results of methylation analysis of dephosphorylated oligosaccharides indicated the presence of five sugar residues: terminal Glc, 3-substituted heptose Hep, terminal GlcN, 7-substituted Hep and 3,7-substituted heptose. All of the ${ }^{1} \mathrm{H}$ and ${ }^{13} \mathrm{C}$ NMR spectra of the isolated core oligosaccharides contained main signals for five anomeric protons and carbons, and in addition a 3-deoxy-D-manno-oct-2-ulosonic acid (Kdo) spin system confirming hexasaccharide structures (not shown). The ${ }^{31} \mathrm{P}$ NMR spectra indicated heterogeneity among the isolated core oligosaccharides. The observed heterogeneity concerned the substitutions of phos- phate esters, diphosphomonoesters, diphosphodiesters and ethanolamine.

The positive mode FAB mass spectrum of the mixture of core oligosaccharides obtained after mild acid hydrolysis of LPS was similar to the spectrum obtained by Muller-Loennies et al. (1994; 1999) (Fig. 1A). Ions at $\mathrm{m} / z$ $1218.04(\mathbf{M}+\mathrm{P}+\mathrm{H})^{+}$and $1341.03(\mathbf{M}+\mathrm{P}+\mathrm{PEtn}+$ $\mathrm{H})^{+}$confirmed the calculated molecular mass of the core hexasaccharide (M) of LPS J5 (Fig. 1B) substituted with one phosphate group (P) and an additional 2-aminoethanol

\section{B}

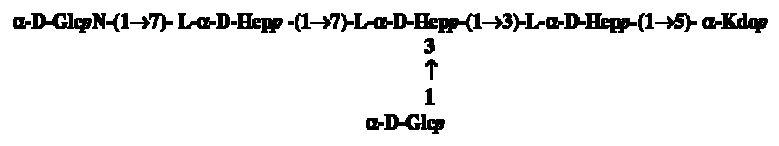

$\mathbf{A}$

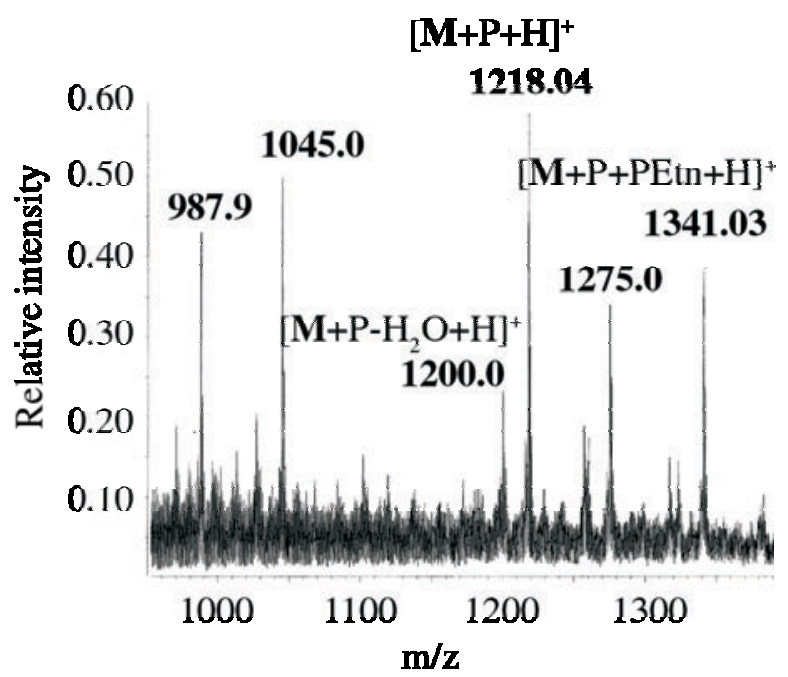

Figure 1. (A) Fragment of FAB-MS mass spectrum of the core oligosaccharide fraction obtained by mild acid hydrolysis of $E$. coli J5 LPS.

The core oligosaccharide fraction was obtained by mild acid hydrolysis of LPS with $1.5 \%$ acetic acid. The reaction mixture was centrifuged to separate lipid A and freeze-dried supernatant was fractionated by gel filtration. The spectrum was obtained in the positive mode using glycerol as a matrix. (B) Structure of the core hexasaccharide (M, molecular ion) of LPS E. coli J5 as reported (Muller-Loennies et al., 1994; 1999). $\alpha$-D-Gl$\mathbf{c p N}$, 2-amino-2-deoxy-D-glucopyranose (L-glucosamine); $\alpha$-D-Glcp, $\alpha$-D-glucopyranose; L- $\alpha$-D-Hepp, L-glycero- $\alpha$-D-manno-heptopyranose; $\alpha$-Kdop, 3-deoxy- $\alpha$-Dmanno-oct-2-ulopyranosonic acid. 
phosphate (PEtn). The ion at $m / z 987.9$ represented an oligosaccharide composed of four sugar residues - two Hep, one Glc and one Kdo substituted with a phosphate group and an additional 2-aminoethanol phosphate.

The molecular ions at $\mathrm{m} / z 1045.0$ and 1275.0 (Fig. 1B) corresponded to the glycoforms additionally substituted with a glycine residue as indicated by the mass difference of $57 \mathrm{Da}$ in comparison with the ions at $m / z \quad 987.9$ and 1218.04, respectively. Similar results were also obtained by MALDI-TOF mass spectrometry. Structural data confirmed the known structure of the core oligosaccharide isolated from $E$. coli J5 LPS and its heterogeneity that is a result of differences in the primary structure of the carbohydrate backbone and nonstoichiometric substitutions by phosphate residues and PEtn. The presence of glycine in the core region of LPS was observed previously (Li et al., 2001; Niedziela et al., 2002) and it contributes to the overall heterogeneity of the core oligosaccharides.

The $E$. coli J5 core oligosaccharide-tetanus toxoid conjugate

The core oligosaccharide was selectively oxidised in the Hep-Kdo region to achieve, on average, a single aldehyde group per molecule. The modified core oligosaccharide was used to obtain a covalent conjugate with tetanus toxoid using reductive amination. The calculated molar ratio of the core oligosaccharide to tetanus toxoid was 9:1.

\section{The anti-conjugate sera}

The conjugate and killed E. coli J5 bacteria were used to immunise rabbits in order to obtain anti-LPS antibodies. The antibody level in the immune sera was determined in a quantitative microprecipitin test with homologous lipopolysaccharide. E. coli J5 LPS precipitated in the equivalent point $1.6 \mathrm{mg}$ of $\mathrm{Ab}$ $\mathrm{ml}^{-1}$ of anti-conjugate serum and $0.7 \mathrm{mg}$ of $\mathrm{Ab}$ $\mathrm{ml}^{-1}$ of antiserum against whole bacterial cells. The conjugate of core oligosaccharide of $E$. coli J5 LPS was a strong immunogen yielding a high level of anti-OS core antibodies.

\section{ELISA assay}

The reaction of both sera with lipopolysaccharides isolated from rough and smooth strains of various bacteria were tested by ELISA. The reactions of the antisera with rough $E$. coli J5, R1, R2, R3, R4 and Salmonella $\mathrm{Ra}, \mathrm{Rb}_{1}, \mathrm{Rb}_{2}, \mathrm{Rc}, \mathrm{Rd}_{1}, \mathrm{Rd}_{2}$, Re lipopolysaccharides are shown on Fig. 2. The absorbance at $405 \mathrm{~nm}$ obtained with antisera 800-fold, 3200-fold and 25600-fold diluted

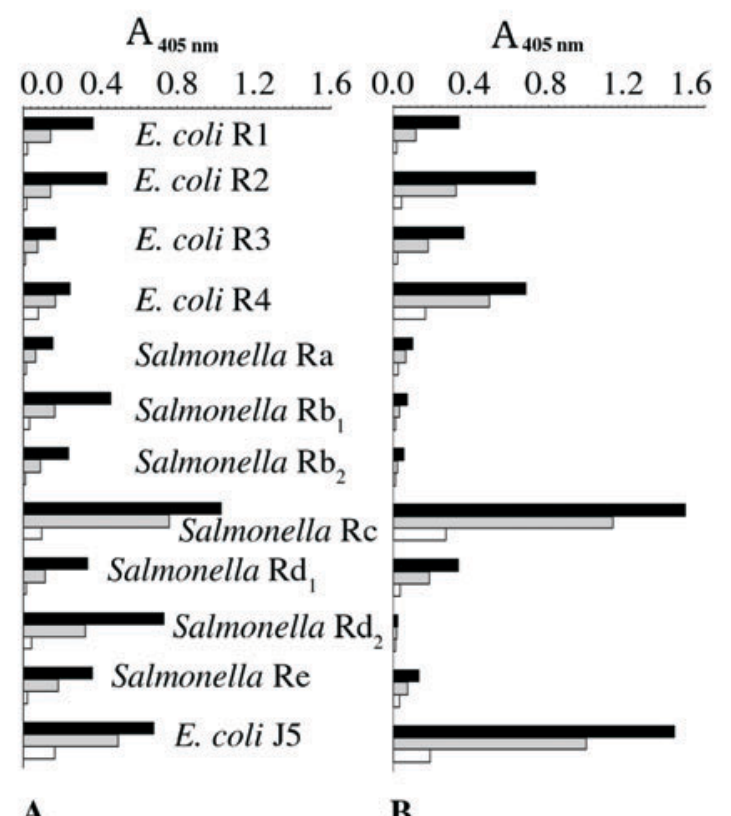

Figure 2. Comparison of the reaction of anti-E. coli J5 serum (A) and anti-E. coli OS J5-TT serum (B) with different lipooligosaccharides isolated from rough strains of bacteria in enzyme-linked immunosorbent assay (ELISA).

Wells were coated using $10 \mu \mathrm{g} / \mathrm{ml}$ solutions of lipooligosaccharides. Casein (2\%) was used to block the surface of the plate and the wells were filled with serial two-fold dilutions of the sera (initial dilution: 1:100). Goat anti-rabbit IgG conjugated with alkaline phosphatase as a second antibody and p-nitrophenylphosphate as substrate were used for colour development.

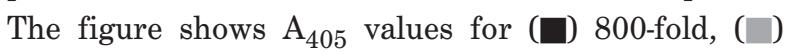
3200-fold, ( $\square$ ) 25600-fold serum dilutions. Data represent the means of three replicates. Standard deviations did not exceed $5 \%$ and is not shown. 
were compared. Both sera reacted strongly with homologous LPS of E. coli J5 and Salmonella Rc, but the cross-reaction profiles were different for each serum. Lipooligosaccharide of Salmonella $\mathrm{Rd}_{2}$ reacted strongly with the serum against $E$. coli J5. The anti-endotoxin serum raised against the core oligosaccharidetetanus toxoid conjugate showed broader specificity. This serum also reacted strongly at high concentration with LPS of $E$. coli representing $\mathrm{R} 2$ an $\mathrm{R} 4$ core type. Weak reactions were observed for the same LPSs with the anti-endotoxin serum obtained against $E$. coli $\mathrm{J} 5$. The strong reaction of the anti-E. coli J5 serum with LPS possessing $\mathrm{Rd}_{2}$ core structure and even the Re type, suggested that deep core epitopes exposed on $E$. coli J5 bacterial cells are responsible for the induction of specific antibodies that are able to react with the Kdo-heptose region of LPS. The $E$. coli J5 core oligosaccharide present in the conjugate contained only one Kdo residue at the reducing end and was linked to the protein through a modified Kdo-heptose region. Such an immunogen exposes mainly epitopes of the terminal hexose region and induces antibodies against Rc and complete core structures.

Lipopolysaccharides isolated from various bacterial strains were used in ELISA to determine the ability of both antisera described above to recognise core epitopes in the structure of LPS of smooth bacteria (Fig. 3). LPSs of E. coli, P. shigelloides, Klebsiella pneumoniae, Citrobacter freundii, S. typhimurium, Hafnia alvei, Shigella sonnei $\mathrm{Ph}$ I and B. pertussis presenting different types of core oligosaccharides were used in ELISA. Both antisera showed similar specificity in the reaction with most of the lipopolysaccharides isolated from smooth and rough bacterial strains representing identical (E. coli O39, O64, S. sonnei Phase I and II, S. flexneri $2 b$ ) or related (E. coli O14, O100, H. alvei PCM 31 and 1207) inner core structure. The less distinct reactions with endotoxins of the antibacterial serum in comparison to the anti-conjugate serum were also found in this experiment.
$\mathrm{A}_{405 \mathrm{~nm}} \quad \mathrm{~A}_{405 \mathrm{~nm}}$

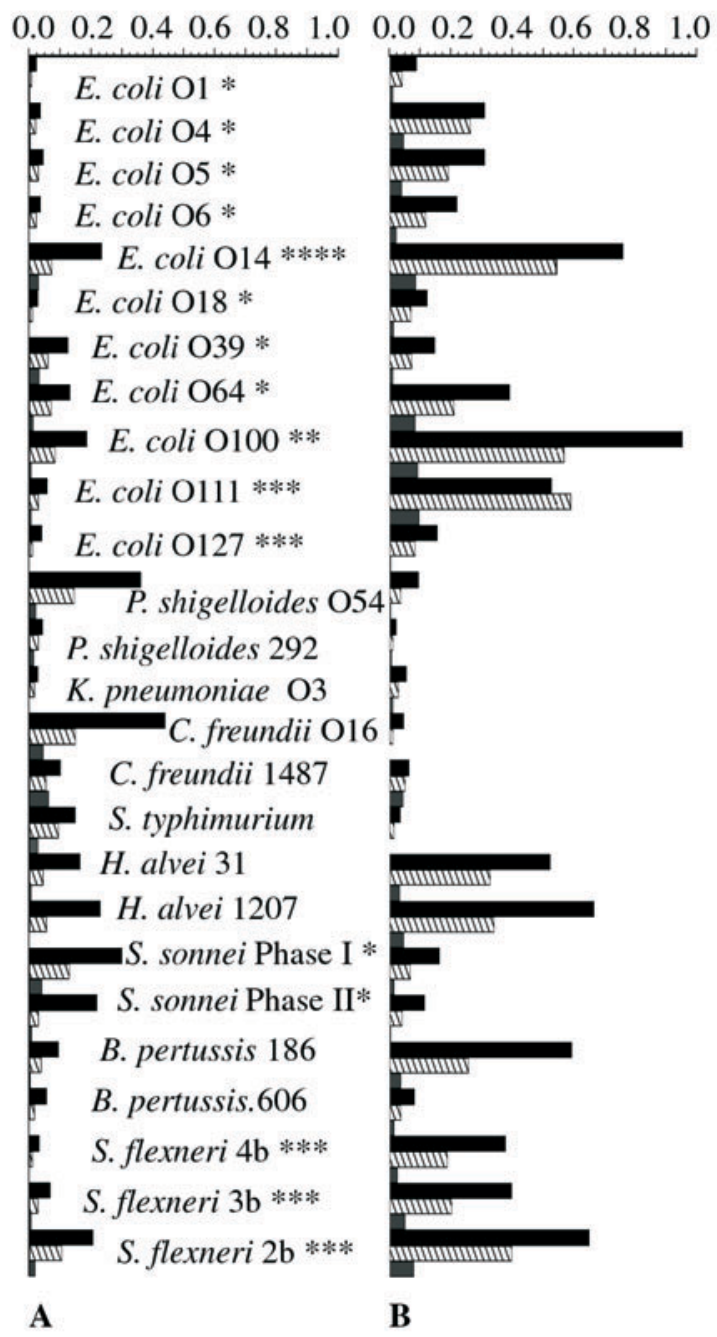

Figure 3. Comparison of the reaction of anti-E. coli J5 serum (A) and anti-E. coli OS J5-TT serum (B) with different LPSs of smooth and rough strains of bacteria in enzyme-linked immunosorbent assay (ELISA).

The symbols $\left({ }^{*}\right),\left({ }^{* *}\right)$ and $\left({ }^{* * *}\right)$ represent $\mathrm{R} 1, \mathrm{R} 2$ and $\mathrm{R} 3$ core types of LPS, respectively. The figure shows $\mathrm{A}_{405}$

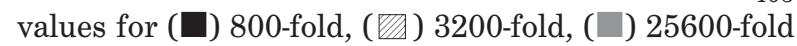
serum dilutions. Data represent the means of three replicates. Standard deviation did not exceed $5 \%$ and is not shown. Assay conditions as in Fig. 2.

The strongest reactions of both sera were observed with LPS of $E$. coli O14, O100, $S$. flexneri $2 \mathrm{~b}$ and $H$. alvei 1207 . The anti-conjugate serum showed additionally a distinct reaction with LPS of $B$. pertussis 186. In contrast to earlier studies (Lugowski et al., 1996a) this antiserum reacted strongly even at low 
concentration with $E$. coli 0111 LPS. The antiserum directed against $E$. coli $\mathrm{J} 5$, in contrast to the anti-conjugate serum, reacted distinctly with LPS of $P$. shigelloides $\mathrm{O} 54, C$. freundi $\mathrm{O} 16$ and $S$. sonnei $\mathrm{Ph} \mathrm{I}$. Antibodies present in this serum did not recognize epitopes in the LPS of $E$. coli O111:B4. These results are in agreement with published data (Sakulramrung \& Domingue, 1985; Appelmelk et al., 1993).

\section{Immunoblotting}

In order to explain which region of lipopolysaccharides is involved in the reaction with specific sera the reactivity of the anti-conjugate and anti- $E$. coli J5 serum with lipopolysaccharides of various strains of smooth bacteria was compared in immunoblotting experiments. Lipopolysaccharides were separated by SDS/PAGE and transblotted from the gel onto nitrocellulose. All of the LPSs of smooth strains showed a high molecular mass ladder-like pattern of bands in SDS/PAGE analysis (Fig. 4A).

All the observed reactions with the anti-conjugate serum concerned mainly the fast migrating LPS fractions non-substituted with O-specific chains. Antibodies against OS J5-TT conjugate reacted with LPSs possessing identical (E. coli O1, O18, O64, O111, S. sonnei Phase I) and related (E. coli O10, O100, $H$. alvei PCM 31 and 1207, B. pertussis 186 and $606)$ inner core oligosaccharide. The lack of structural similarity between core oligosaccharide of $P$. shigelloides CNCTC 113/92 and $E$. coli J5 was responsible for the absence of reactions of that LPS with anti-conjugate serum. Both sera reacted strongly with core regions of LPS of E. coli O100, H. alvei 1207 and 31 (Fig. 4B and C). Lipopolysaccharides showing strong reactions in ELISA only with the anti-E. coli J5 serum, reacted in immunoblotting in the regions of slow migrating fractions. The immunoblotting pattern suggested that slight protein contaminants present in some LPS samples were involved in the observed reactions. LPS fractions obtained dur-

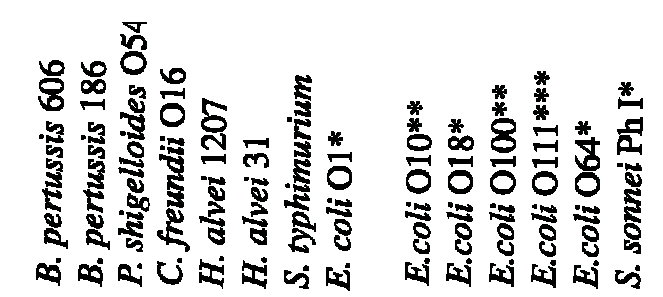

$\mathbf{A}$

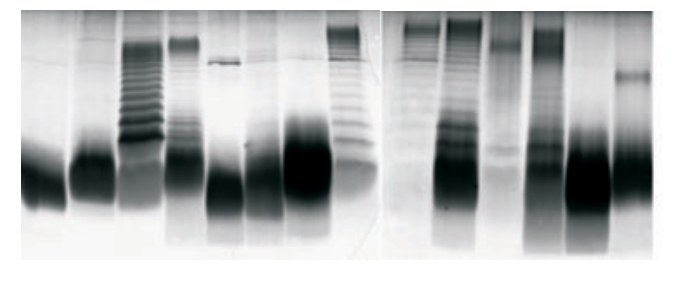

B
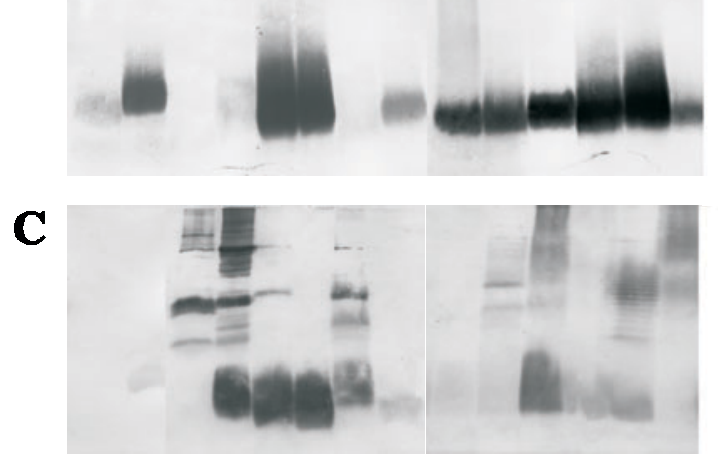

Figure 4. Silver-stained SDS/PAGE of various lipopolysaccharides (A). Immunoblots of the lipopolysaccharides with anti-OS J5-TT conjugate serum (B) and with anti-E. coli J5 serum (C).

LPSs were separated by SDS/PAGE. Suspensions (1 $\mathrm{mg} \mathrm{ml}^{-1}$ ) were mixed with sample buffer and $8 \mu \mathrm{l}$ portions of LPSs were applied to a gel. Electrophoresis was performed in a $15 \%$ acrylamide slab gel. LPSs were detected by silver staining or were analysed by blotting with antibodies directed against anti-OS J5-TT conjugate (200-fold diluted).

ing phenol/water extraction contain only traces of proteins not detectable by standard analytical procedures such as SDS/PAGE silver-staining method, UV spectrophotometric assay and MALDI-TOF mass spectrometry. LPS of $C$. freundii was the only one that also reacted with the anti- $E$. coli J5 serum in the region of fast migrating fractions.

\section{Flow cytometry (FACS)}

The ability of the sera examined to recognise core oligosaccharide epitopes of LPS on the surface of live bacteria were observed using 
FACS analysis (Fig. 5). Three smooth strains were chosen for the experiment: $E$. coli O39, $\mathrm{O} 100$ and $\mathrm{O} 111$ representing LPS of the R1, R2 and R3 core types, respectively. The per-
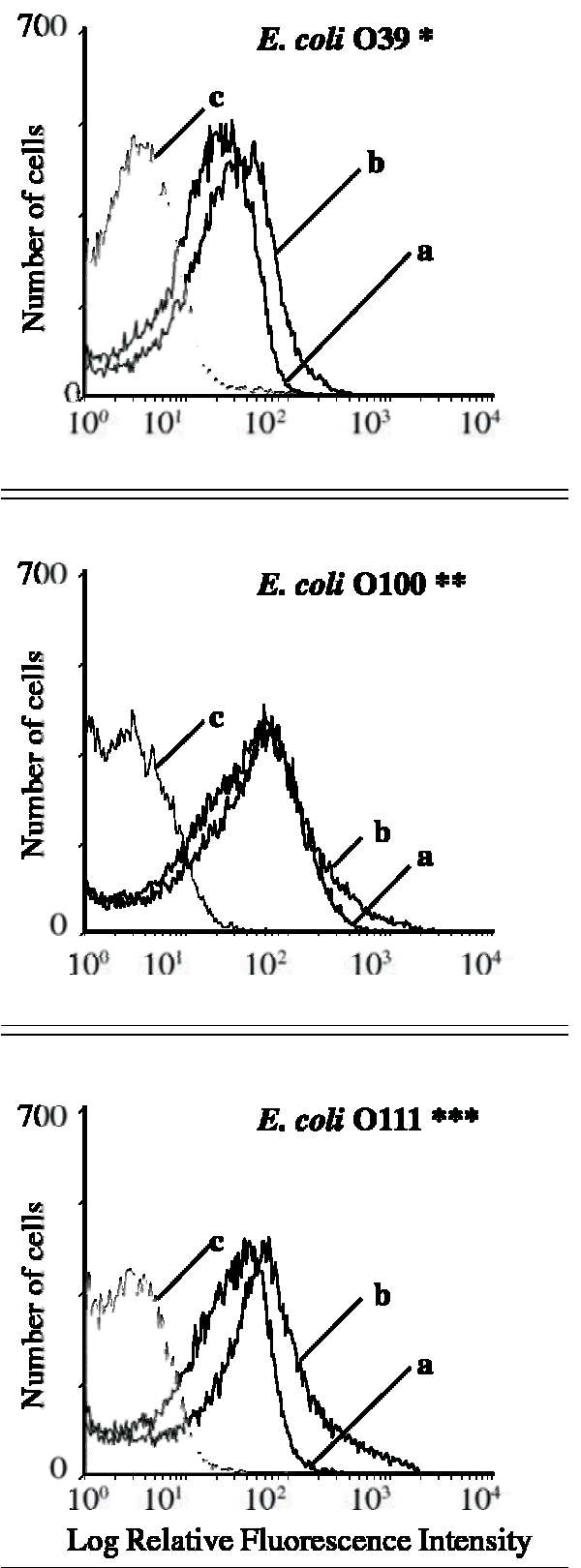

Figure 5. FACS analysis of the binding to smooth intact bacteria ( $E$. coli $039,0100,0111$ ) of (a) anti- $E$. coli J5 antibodies, (b) anti-OS J5-TT conjugate antibodies and (c) antibodies from non-immune rabbits.

Bacteria were suspended in PBS to an absorbance of 0.6 at $600 \mathrm{~nm}\left(4 \times 10^{8} \mathrm{cfu} \mathrm{ml}^{-1}\right)$ and mixed with antiserum. All antisera were 100 -fold diluted. Non-immune sera were employed as negative controls. The symbols $\left({ }^{*}\right),\left({ }^{* *}\right)$ and $\left({ }^{* * *}\right)$ stand for R1, R2 and R3 core types of LPS, respectively. centage of bacteria exhibiting fluorescence above background level was in excess of $95 \%$ for all tested strains and the ability of both sera to bind to bacterial cells was similar. The highest intensity of fluorescence was observed for $E$. coli $\mathrm{O} 100$. The similar reactivity of the anti $E$. coli J5 serum, containing lower level of anti-LPS antibodies than present in the anti-conjugate serum, is probably caused by the presence of antibodies against other bacterial surface antigens. This, being in agreement with earlier studies, suggests that antibodies directed against outer membrane proteins can play important role in the cross-reactivity of the anti-E. coli J5 serum.

\section{ELISA inhibition assay}

Core oligosaccharides of various core types were isolated from E. coli and Salmonella lipopolysaccharides (Fig. 6). The inhibitory ac-

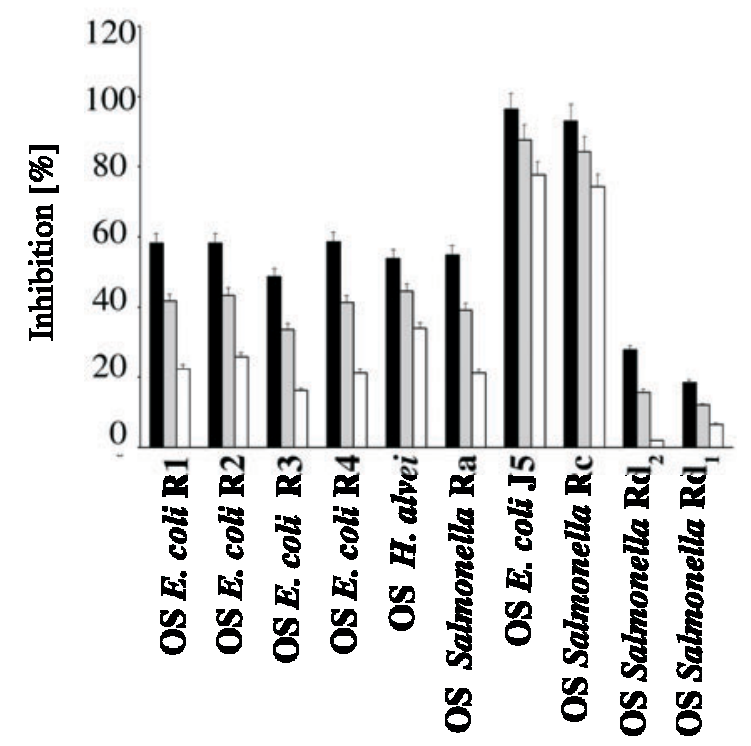

Figure 6. Inhibitory effect of different core oligosaccharides on the reaction of anti-OS J5-TT serum with $E$. coli J5 LPS in ELISA.

The antiserum $(100 \mu \mathrm{l})$ at a concentration twice as high as that giving $\mathrm{A}_{405}$ in the range 0.8-1.1 was mixed with $100 \mu \mathrm{l}$ of serial two-fold dilutions of inhibitor and transferred into wells coated with $E$. coli J5 LPS (10 $\mu \mathrm{g} / \mathrm{ml}, 100 \mu \mathrm{l})$. The figure shows the results for concentrations of inhibitors: $(\square) 200 \mu \mathrm{g} \mathrm{ml}^{-1}$, ( $50 \mu \mathrm{g} \mathrm{ml}^{-1}$, () $10 \mu \mathrm{g} \mathrm{ml}^{-1}$. Data represent the means of three replicates. Standard deviation did not exceed $5 \%$ and is not shown. 
tivity of isolated oligosaccharides in reactions between the anti-conjugate serum and $E$. coli J5 LPS was compared by ELISA. The reactions were inhibited by $77 \%$ to $100 \%$ by $E$. coli J5 and Salmonella Rc core oligosaccharide at 10-200 $\mu \mathrm{g} \mathrm{ml}^{-1}$. The oligosaccharides representing $E$. coli R1, R2, R3, R4, Salmonella Ra and H. alvei core types showed similar activity, i.e. they inhibited the binding of the anti-conjugate serum to $E$. coli J5 LPS. The inhibition for these oligosaccharides was in the range of $15-60 \%$ for the concentrations $10-200 \mu \mathrm{g} \mathrm{ml}^{-1}$. The inhibitory activity of $\mathrm{Rd}$ core type oligosaccharides was significantly lower. These data suggested that immunisation with the OS J5-TT conjugate did not stimulate rabbits to produce antibodies directed against the heptose region of LPS which was probably not properly exposed in this immunogen.

\section{Inhibition of cytokines and NO induction}

LPS of E. coli 0100 that showed the most distinct reactions with both sera in serological tests was used to stimulate IL-6, TNF $\alpha$ and NO production by the macrophage-like cell line J-774A.1. The anti-conjugate OS J5-TT and anti-E. coli J5 sera were used to inhibit this stimulation. The results are shown in Fig. 7. There were no inhibitory effects of the sera examined in comparison with non-immune serum.

It was shown in numerous previous studies (Dunn \& Ferguson, 1982; Bhattacharjee et al., 1994; 1996; Hogan et al., 1999; Cross et al., 2001) that anti-rough mutant $E$. coli J5 serum containing anti-LPS antibodies protected against challenge with heterologous Gramnegative bacteria or smooth LPS. We expected that anti-OS J5-TT serum possessing higher level of anti-J5 LPS core oligosaccharide antibodies than anti-E. coli J5 serum would show a better protective activity. Instead, we found that both sera were inactive even if the lipopolysaccharide of E. coli $\mathrm{O} 100$ was chosen for the challenge. Our earlier studies showed that antiserum obtained against a
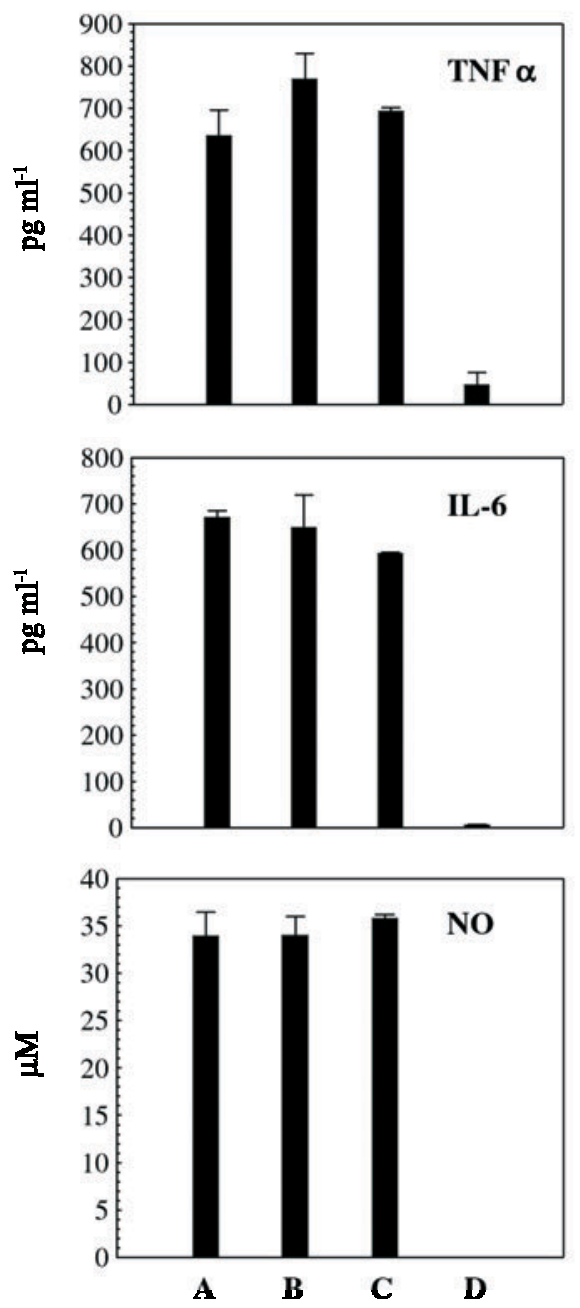

Figure 7. Effect of anti-OS J5-TT conjugate and anti- $E$. coli J5 serum on TNF $\alpha$, IL-6 and NO production by J-774A.1 macrophages stimulated with LPS of E. coli 0100.

Murine macrophage cell line J774A.1 $\left(1 \times 10^{6}\right.$ cells $/$ well) was stimulated with $10 \mathrm{ng}$ of LPS. Supernatants were collected after $4 \mathrm{~h}, 24 \mathrm{~h}$ and $48 \mathrm{~h}$ for TNF $\alpha$, IL-6 and NO determination, respectively. TNF $\alpha$ concentration in the supernatants was determined in the cytotoxic assay using WEHI 164.13 bioassay. IL-6 activity was determined using the OptEIA ${ }^{\mathrm{TM}}$ kit. Total nitrite $\left(\mathrm{NO}_{2}{ }^{-}\right)$concentration in the supernatants was determined by the Griess reaction in $100 \mu \mathrm{l}$ of the test samples. Nitrate was reduced by nitrate reductase. (A) LPS + anti-OS J5-TT serum, (B) LPS + anti-E. coli J5 serum, (C) LPS + non-immune serum, (D) PBS + medium. Data are expressed as means \pm S.D. of three replicates.

conjugate of the core oligosaccharide of LPS E. coli R1 with tetanus toxoid (OS R1-TT) attenuated the release of LPS-induced TNF $\alpha$ in vitro as well as in vivo (Lugowski et al., 1996b). 
Lipooligosaccharide isolated from $E$. coli R1 possess complete structure of core OS containing both hexose and heptose regions. Antibodies against OS R1-TT serum recognise the complete core region present in LPSs of smooth bacterial strains. E. coli $\mathrm{J} 5$ is a rough mutant possessing non-complete core oligosaccharide of Rc type. This structure is an inner part of the complete core and is substituted with the sugars of the hexose region in the LPS of smooth bacterial strains. It may be assumed that antibodies directed against sugars present at the non-reducing end of complete core structure are responsible for the protective activity of the anti-conjugate serum. Antibodies of such specificity are not present in anti-OS J5-TT serum. This is in agreement with some earlier suggestions of other authors (Appelmelk et al., 1993; Appelmelk et al., 1986; Evans et al., 1992) that the protective effects of anti-E. coli J5 serum were caused by the presence of bacterial revertants with complete $\mathrm{R} 3$ core type in the vaccine. The strain of $E$. coli J5 used in our experiments possesses only non-complete core region in LPS, which was confirmed in the structural analysis of isolated core oligosaccharide.

\section{R E F E R E N C E S}

Appelmelk BJ, Rapson NT, Verweij-van Vught AM, Maaskant JJ, Hekker TA, Peerbooms PG, MacLaren DM, Thijs LG. (1986) Heterogeneity of Escherichia coli J5 vaccines. Lancet.; 2: 1273-4.

Appelmelk BJ, Maaskant JJ, Verweij-van Vught AM, Van der Meer NM, Thijs BG, MacLaren DM. (1993) Antigenic and immunogenic differences in lipopolysaccharides of Escherichia coli $\mathrm{J} 5$ vaccine strains of different origins. $J$ Gen Microbiol.; 139: 2641-7.

Bhattacharjee AK, Opal SM, Palardy JE, Drabick JJ, Collins H, Taylor R, Cotton A, Cross AS. (1994) Affinity-purified Escherichia coli J5 lipopolysaccharide-specific IgG pro- tects neutropenic rats against Gram-negative bacterial sepsis. J Infect Dis.; 170: 622-9.

Bhattacharjee AK, Opal SM, Taylor R, Naso R, Semenuk M, Zollinger WD, Moran EE, Young L, Hammack C, Sadoff JC, Cross AS. (1996) A noncovalent complex vaccine prepared with detoxified Escherichia coli J5 (Rc chemotype) lipopolysaccharide and Neisseria meningitidis group B outer membrane protein produces protective antibodies against Gram-negative bacteremia. J Infect Dis.; 173: 1157-63.

Brauner A, Kallenius G, Wrangsell G, Wretlind B, Svenson SB. (1986) Antibody responses to Escherichia coli J5 lipopolysaccharide and to Salmonella porin in patients with bacteremia. Microb Pathog.; 1: 475-81.

Cross AS, Opal SM, Warren HS, Palardy JE, Glaser K, Parejo NA, Bhattacharjee AK. (2001) Active immunization with a detoxified Escherichia coli J5 lipopolysaccharide group $B$ meningococcal outer membrane protein complex vaccine protects animals from experimental sepsis. J Infect Dis.; 183: 1079-86.

Dunn DL, Ferguson RM. (1982) Immunotherapy of Gram-negative bacterial sepsis: enhanced survival in a guinea pig model by use of rabbit antiserum to Escherichia coli J5. Surgery.; 92: 212-9.

Elbein AD, Heath EC. (1965) The biosynthesis of cell wall lipopolysaccharide in Escherichia coli. I. The biochemical properties of a uridine diphosphate galactose 4-epimeraseless mutant. J Biol Chem.; 240: 1919-25.

Espevik T, Nissen-Meyer J. (1986) A higly sensitive cell line, WEHI 164 clone 13, for measuring cytotoxic factor/tumor necrosis factor from human monocytes. J Immunol Methods.; 95: 99-105.

Evans ME, Pollack M, Koles NL, Hardegen NJ, Panopoulos D. (1992) Lipopolysaccharide heterogeneity in Escherichia coli J5 variants: analysis by flow cytometry. J Infect Dis.; 166: 803-11.

Galanos C, Luderitz O, Westphal O. (1969) A new method for the extraction of $\mathrm{R}$ lipopolysaccharides. Eur J Biochem.; 9: 245-9. 
Hakomori S. (1964) A rapid permethylation of glycolipid and polysaccharide catalyzed by methylsulphinyl carbanion in dimethyl sulphoxide. J Biochem.; 55: 205-8.

Hansen BM, Nielsen SE, Berg K. (1989)

Re-examination and further development of a precise and rapid dye method for measuring cell growth/cell kill. J Immunol Methods.; 119: $203-10$

Hellman J, Warren HS. (1999) Antibodies against bacterial membrane proteins. $J$ Endotoxin Res.; 5: 213-5.

Hellman J, Zanzot EM, Loiselle PM, Amato SF, Black KM, Ge YM, Kurnick JT, Warren HS. (1997) Antiserum against Escherichia coli J5 contains antibodies reactive with outer membrane proteins of heterologous Gram-negative bacteria. $J$ Infect Dis.; 176: 1260-8.

Hellman J, Loiselle PM, Zanzot EM, Allaire JE, Tehan MM, Boyle LA, Kurnick JT, Warren HS. (2000) Release of Gram-negative outer-membrane proteins into human serum and septic rat blood and their interactions with immunoglobulin in antiserum to Escherichia coli J5. J Infect Dis.; 181: 1034-43.

Hogan JS, Bogacz VL, Aslam M, Smith KL. (1999) Efficacy of an Escherichia coli J5 bacterin administered to primigravid heifers. J Dairy Sci.; 82: 939-43.

Holst O, Ulmer AJ, Brade H, Flad H, Rietschel E. (1996) Biochemistry and cell biology of bacterial endotoxins. FEMS Immunol Med Microbiol.; 16: 83-104.

Hustinx WNM, Kraaijeveld K, Hoepelman AIM, Verhoef J. (1997) Cross-protection by anti-core glycolipid antibodies: evidence from animal experiments. $J$ Antimicrob Chemother.; 40: $475-83$.

Jennings HJ, Lugowski C. (1982) Tetanus toxoid conjugates of the meningococcal polysaccharides. Bact Vaccines.; 4: 247-53.

Kabat EA, Mayer MM. (1967) Precipitin reaction. In Experimental Immunochemistry. pp 22-96. Charles C Thomas, Springfield.

Laemmli UK. (1970) Cleavage of structural proteins during the assembly of the head of bacteriophage T4. Nature.; 227: 680-5.
Li JJ, Bauer SHJ, Mansson M, Moxon ER, Richards JC, Schweda EKH. (2001) Glycine is a common substituent of the inner core in Haemophilus influenzae lipopolysaccharide. Glycobiology.; 11: 1009-15.

Lugowski C, Romanowska E. (1978) Enterobacterial common antigen: isolation from Shigella sonnei, purification and immunochemical characterization. Eur J Biochem.; 91: 89-97.

Lugowski C, Jachymek W, Niedziela T, Rowinski S. (1996a) Serological characterisation of anti-endotoxin sera directed against the conjugates of oligosaccharide core of Escherichia coli type R1, R2, R3, J5 and Salmonella Ra with tetanus toxoid. FEMS Immunol Med Microbiol.; 16: 21-30.

Lugowski C, Niedziela T, Jachymek W. (1996b) Anti-endotoxin antibodies directed against Escherichia coli R-1 oligosaccharide core-tetanus toxoid conjugate bind to smooth, live bacteria and smooth lipopolysaccharides and attenuate their tumor necrosis factor stimulating activity. FEMS Immunol Med Microbiol.; 16: 31-8.

Mosmann T. (1983) Rapid colorimetric assay for cellular growth and survival: application to proliferation and cytotoxicity assays. $J$ Immunol Methods.; 65: 55-63.

Muller-Loennies S, Holst O, Brade H. (1994) Chemical structure of the core region of Escherichia coli J-5 lipopolysaccharide. Eur J Biochem. 224, 751-60.

Muller-Loennies S, Holst O, Lindner B, Brade H. (1999) Isolation and structural analysis of phosphorylated oligosaccharides obtained from Escherichia coli J-5 lipopolysaccharide. Eur J Biochem.; 260: 235-49.

Niedziela T, Petersson C, Helander A, Jachymek W, Kenne L, Lugowski C. (1996) Structural studies of the O-specific polysaccharide of Hafnia alvei strain 1209 lipopolysaccharide. Eur J Biochem.; 237: 635-41.

Niedziela T, Lukasiewicz J, Jachymek W, Dzieciatkowska M, Lugowski C, Kenne L. (2002) Core oligosaccharides of Plesiomonas shigelloides 054:H2 (strain CNCTC 113/92). Structural and serological analysis of the 
lipopolysaccharide core region, the O-antigen biological repeating unit, and the linkage between them. J. Biol. Chem.; 277: 11653-63.

Petersson C, Niedziela T, Jachymek W, Kenne L, Zarzecki P, Lugowski C. (1997) Structural studies of the O-specific polysaccharide of Hafnia alvei strain PCM 1206 lipopolysaccharide containing D-allothreonine. Eur J Biochem.; 244: 580-6.

Romanowska A, Katzenellenbogen E, Kulakowska M, Gamian A, Witkowska D, Mulczyk M, Romanowska E. (1988) Hafnia alvei lipopolysaccharides: isolation, sugar composition and SDS/PAGE analysis. FEMS Immunol Med Microbiol.; 1: 151-5.

Sakulramrung R, Domingue GJ. (1985) Cross-reactive immunoprotective antibodies to Escherichia coli 0111 rough mutant J5. J Infect Dis.; 151: 995-1004.
Schmidt HHW. (1995) Determination of nitric oxide via measurement of nitrite and nitrate in culture media. Biochemica.; 2: 22 .

Tsai CM, Frasch CE. (1982) A sensitive silver stain for detecting lipopolysaccharides in polyacrylamide gels. Anal Biochem.; 119: $115-9$.

Voller A, Draper C, Bidwell DE, Bartlett A. (1975) Microplate enzyme-linked immunosorbent assay for Chagas' disease. Lancet.; 1: 426-8.

Ziegler EJ, Douglas H, Sherman JE, Davis CE, Braude AI. (1973) Treatment of E. coli and Klebsiella bacteremia in agranulocytic animals with antiserum to a UDP-gal epimerase-deficient mutant. J Immunol.; 111: 433-8. 